\title{
Functional Abilities in Children and Adults with the CDKL5 Disorder.
}

Stephanie Fehr ${ }^{1}$ Jenny Downs ${ }^{1,}{ }^{2}$ Gladys $\mathrm{Ho}^{3}$ Nick de Klerk ${ }^{1}$ David Forbes ${ }^{4}$ John Christodoulou ${ }^{4}$ Simon Williams ${ }^{5}$ Helen Leonard. ${ }^{1}$

1 Telethon Kids Institute, The University of Western Australia, Perth, Western Australia, Australia.

${ }^{2}$ School of Physiotherapy and Exercise Science, Curtin University, Perth, Western Australia, Australia.

${ }^{3}$ Western Sydney Genetics Program, Children's Hospital at Westmead, Sydney, Australia

Discipline of Paediatrics \& Child Health, University of Sydney, Sydney, Australia

${ }^{4}$ School of Paediatrics and Child Health, University of Western Australia, Perth, Western Australia

${ }^{5}$ Department of Neurology and Rehabilitation, Princess Margaret Hospital, Perth, Western Australia

Address correspondence to:

Associate Professor Helen Leonard

Telethon Kids Institute, 100 Roberts Road, Subiaco, Western Australia, 6008

Telephone: +610894897790

Fax: +610894897700

Email: Helen.Leonard@telethonkids.org.au

Functional abilities in the CDKL5 disorder

Running head:

The CDKL5 disorder 


\section{ABSTRACT}

Functional abilities in the CDKL5 disorder have been described as severely impaired, yet some individuals are able to run and use phrases for speech. Our study investigated gross motor, hand function and expressive communication abilities in individuals with the CDKL5 disorder. Data for 108 females and 16 males registered with the International CDKL5 disorder database and with a pathogenic CDKL5 mutation was analysed. Relationships between functional abilities, age, genotype and gender were analysed using regression models. Over half of the females could sit on the floor and nearly a quarter could walk 10 steps. Fewer males could complete these tasks although one boy was able to sit, walk and run. Most females and few males were able to pick up a large object. Females mostly used gestures to communicate whilst males mostly used other forms of non-verbal communication. Compared to those with no functional CDKL5 protein, individuals with truncating variants after aa 781 were more likely to be able to stand (OR 5.7, 95\% CI 1.2, 26.6) or walk independently $(4.3,95 \% \mathrm{CI} 0.9,20.5)$, and use more advanced communication methods such as words (OR 6.1, 95\% CI 1.524.2). Although abilities were markedly impaired for the majority with the CDKL5 disorder, some females and a few males had better functional abilities. This variability may be related to underlying gene variants, with females with a late truncating variant having better levels of ability than those with no functional protein.

\section{KEYWORDS}

Functional abilities

Genotype

Epileptic encephalopathy

\section{CDKL5}


Disability

\section{INTRODUCTION}

The CDKL5 disorder is caused by variants in the cyclin-dependent kinase-like 5 (CDKL5) gene.[Fehr et al., 2013; Kalscheuer et al., 2003; Weaving et al., 2004a] Clinical features identified to date include early-onset seizures (generally within the first three months of life), severe global developmental delay, abnormal muscle tone, hand stereotypies, gastrointestinal problems and bruxism.[Fehr et al., 2013] Most studies of the CDKL5 disorder have been limited to case studies or small case series and whilst functional abilities have mostly been described as severely impaired,[Fehr et al., 2013; Hagebeuk et al., 2013; Liang et al., 2011; Olson and Poduri 2012; White et al., 2010] variability in the clinical features has also been reported. It appears that some individuals are less severely affected, in terms of motor abilities and are able to walk[Martínez et al., 2012; Pini et al., 2013; Weaving et al., 2004a] and even run.[Bartnik et al., 2011] Expressive communication seems to be mostly limited to vocalisations and babble,[Artuso et al., 2010; Evans et al., 2005; Jähn et al., 2013; Nemos et al., 2009; Tao et al., 2004] although some girls are able to use words in phrases.[Archer et al., 2006; Martínezet al., 2012; Weaving et al., 2004b] Hand function has been less well documented,[Bahi-Buisson et al., 2008; Bartnik et al., 2011; Hagebeuk et al., 2013; Martínez et al., 2012; Olson and Poduri 2012; Piniet al., 2013] but would appear to be absent or limited for most.[Artuso et al., 2010; Evans et al., 2005; Jähn et al., 2013; Nemos et al., 2009; Tao et al., 2004] 
Despite this apparent variability in the functional abilities there have been no large studies investigating the spectrum. We recently used time to event analysis to investigate specifically the attainment of developmental milestones in the CDKL5 disorder.[Fehr et al., 2015] Approximately two thirds of females and one third of males learnt to sit. A quarter of females had attained independent walking by four and a half years but independent walking was rare in males. One in ten females was able to produce single words by 18 months of age but only one of 18 males acquired use of words.[Fehr et al., 2015] This is the extent of the information available on functional abilities in these and other domains in children and adults of various ages with the CDKL5 disorder and there is limited understanding of any relationship with genotype. There is a need to increase knowledge about this disorder to inform the natural history and guide clinical management. The aim of this study was to describe current functional abilities in detail in individuals with the CDKL5 disorder and to investigate the relationships with genotype, age and gender.

\section{METHODS}

The International CDKL5 Disorder Database was established in 2012 and collects information from caregivers of a child with the CDKL5 disorder in the form of online or paper-based questionnaires. Data collection tools were developed in consultation with a consumer reference group, experienced clinicians and review of the literature.[Fehr et al., 2015] Caregivers who had previously provided data to the International Rett Syndrome Phenotype Database (InterRett) were recontacted [Fehr et al., 2013] and invited to participate in this new CDKL5 disorder specific database.[Fehr 
et al., 2015] Cases were included in this study, if their CDKL5 variant affected protein function and information on current functional abilities had been provided.

Because of the marked heterogeneity in individual CDKL5 mutations within our sample, they were grouped according to their predicted structural and functional consequences [Bertani et al., 2006] to investigate the relationship between genotype and functional ability. These groups were a) variants resulting in no functional protein (including variants causing loss of the functional components in the catalytic domain before amino acid (aa) 172 and full gene deletions) b) missense/in-frame variants within the catalytic domain (includes any missense variants within the protein's kinase active region or in-frame variants) c) truncating variants located between aa 172 and aa 781 (includes any variants resulting in a truncation such as nonsense or frameshift variants potentially resulting in maintaining kinase activity but loss of the C-terminal region) and d) truncating variants occurring after aa 781 (maintains kinase activity and majority of the C-terminal region). All identified variants have been listed[Fehr et al., 2015] and were submitted to RettBASE: http://mecp2.chw.edu.au/cdkl5/cdkl5_variant_list.php. Age was categorised as $<1.5$ years; $>1.5$ to $<7$ years, $>7$ to $<13$ years; and $>13$ years. These age groupings were based on broad expected developmental abilities of children in these age groups.

To investigate gross motor abilities for the children less than 1.5 years, a modified version of the Chailey Levels of Ability was used for skills in prone and supine lying, floor and stool sitting, and standing.[Pountney et al., 1999] The scale was modified to 
allow completion by caregivers and we asked them to indicate which of six alternatives best described their child's gross motor ability in each position.

The Rett Syndrome Gross Motor Scale comprises 15 gross motor skills scored on a 4-point scale [Downs et al., 2008] and is suitable for children with a severe disability. For the current study, caregivers were asked to indicate the level of assistance needed by their child. Each item was then coded as needing no assistance; needing some assistance; or unable to complete/needing maximal assistance. The more basic motor skills were described for individuals aged 18 months or older, and the more complex skills of getting up from the floor, bending to touch the floor and running were described for individuals aged three years and older. This avoided children being scored on tasks that were too complex for their chronological age.

Seventeen binary (Yes/No) questions were used to ascertain hand function in relation to skills such as pressing a switch and grasping large and small objects, enabling scoring based on the Rett Syndrome Hand Function Scale.[Downs et al., 2010] The Rett Syndrome Hand Function Scale comprises eight levels ranging from level one (no grasping ability present) to eight (able to pick up small objects using a precise pincer grip and transfer objects from one hand to the other).[Downs et al., 2010] If responses were not clearly indicative of a level, further information was sourced from caregiver comments about hand function and the most likely conservative category was assigned. For description and analyses, hand grasping abilities were grouped as follows: none or limited grasping abilities (level 3 or lower); able to grasp a large but not a small object (level 4); and able to grasp both large and small objects (level 5 and higher). 
Expressive communication was investigated using questions modelled on two areas of the communication matrix.[Rowland and Fried-Oken 2010] Caregivers were asked to indicate the methods of communication their child used to convey either refusal or when requesting an object or experience. Communication methods included: early sounds (such as laughing, screaming and grunting), facial expression, body language (such as twisting body away and kicking), simple gestures (such as tapping an item or pushing it away), complex gestures (such as shaking their head and giving back unwanted item), vocalisations (such as 'uh uh"), concrete symbols (pictures), single words, signs, and language (more than one word or sign language). Each individual was then assigned to one of the three categories based on their most complex method of expressive communication: 1) no observed or simple methods of communication (body language, early sounds, facial expressions and simple gestures); 2) complex gestures, vocalisations and concrete symbols; and 3) spoken language (single words and more than one), sign language and abstract symbols. For statistical analysis relating to communication skills those under two years were excluded, as it would be less likely for them to have attained language.

Approval for this study was provided by the University of Western Australia Human Research Ethics Committee, Perth, Western Australia, Australia (RA/4/1/5024).

\section{Statistical analyses}

Descriptive statistics were used to explore the distribution of functional abilities across gender, age and mutation groups. The variables describing sitting on the floor for 10 seconds, standing for 20 seconds and walking forward 10 steps were re-categorised 
as a binary variable (no assistance needed / assistance needed or unable). Logistic regression was used to assess the relationships between these gross motor skills, mutation group, age group and gender. Multinomial logistic regression was used to assess relationships between the three levels of hand grasping ability and mutation group, age group and gender. Ordinal logistic regression was used to assess relationships between the three communication levels and mutation group, age group and gender, with the odds ratio (OR) for each predictor variable being interpreted as the relative odds of an individual having a higher outcome in the functional ability variable.

\section{RESULTS}

As of May 2014 there were 124 individuals (57 had previously provided data to InterRett [Fehr et al., 2013]) who were eligible for this study. Of these 108 (87\%) were female (median age six years, range three months to 29 years) and $16(13 \%)$ were male (median age five years three months, range 10 months to 22 years eight months). Data on developmental regression was available for 119 individuals, 25 of whom had previously experienced loss of hand function and/or communication skills. This regression coincided with severe bouts of epilepsy or changes in epilepsy management for 17 (68\%) of this group.

\section{Gross motor function of children aged 1.5 years and younger}

Eleven girls and one boy were aged 1.5 years or younger and had modified Chailey Levels of Ability scores. For the girls, six were able to roll from supine onto their side or three from prone to supine and back again. In prone lying, eight were able to lift their head and five could take weight through their arms. Eight could sit on the 
floor independently and one could sit on a stool and stand independently. The boy could roll from supine to prone, move into four-point kneeling, and sit on the floor independently. He needed assistance to sit on a stool and balance in standing.

Gross motor scores for individuals aged over 1.5 years

Gross motor data were available for 97 females. Two thirds $(n=65,67 \%)$ could sit on the floor without support, just over half $(n=51,54 \%)$ could sit on a firm backed chair and almost a third $(n=30,31 \%)$ were able to sit on a stool independently (Table 1). A quarter ( $\mathrm{n}=24)$ were able to stand for 20 seconds, $20(21 \%)$ were able to transition from sitting to standing with no assistance and 22 (23\%) could walk forward 10 steps. For the more complex tasks, nearly a quarter could get up from the floor to standing, $20 \%$ could bend over to touch the floor and return to standing and $13 \%$ were reported to be able to run (Table 1).

Gross motor data were available for 15 males. Most were unable to perform most tasks although four boys could sit on the floor with no assistance and one could complete all tasks independently (Table 1).

\section{Hand function}

Data on hand function were available for 105 females and 16 males. A category of hand grasping could be assigned to all but two of the females (Table 2). Overall 17\% of the females had no ability to grasp objects including seven females who were reported only to be able to press a switch. These individuals were classified with individuals who needed assistance to grasp an object $(35 / 105,34 \%)$, as none could 
grasp an object independently. Otherwise, two thirds could either grasp and pick up a large object (>level 3) $(27 / 103,26 \%$ ) or pick up a large or a small object $41 \%$ (>level 4$)$ (41/103). (Table 2).

Three quarters of the males in the study could not grasp objects, although a quarter could hold an object that was given to them. Otherwise, two could grasp and pick up a large object, and two could pick up small objects also (Table 2).

\section{Expressive Communication}

Information on expressive communication skills was available for all but two of the females. Most females used a variety of methods to communicate although one was reported only to use facial expressions to communicate and two to have no expressive communication. The most frequently used methods of communication were body language (96\%), facial expressions (94\%), early sounds (91\%) and simple gestures (89\%). Over half (63\%) used complex gestures, a quarter used single words, signs or abstract symbols (single words $n=9$ ), one fifth used vocalisations and eight could speak in sentences. After categorisation by their most advanced communication method, the best level of communication used by females was spoken language, sign language and abstract symbols (26\%), complex gestures, followed by vocalisations and concrete symbols (39\%), and simple communication (33\%) (Table 2).

The males in the study also used multiple modes of expressive communication, although compared to females, fewer used complex gestures and vocalisations and three quarters used simpler communication methods (Table 2). 
Relationships between age, genotype, gender and current functional abilities

Univariate and multivariate analyses for gross motor skills are shown in Tables

$3 \& 4$. There were no apparent relationships between age and the abilities to sit, stand or walk in those older than 18 months. Compared to individuals with no functional protein, those with a truncation after aa781 had three times the odds (OR 3.33, 95\% CI 0.56, 16.35) of sitting on the floor, five times the odds (OR 5.66, 95\% CI 1.20, 26.64) of independent standing and four times the odds (OR 4.28, 95\%CI 0.89, 20.50) of independent walking, taking into account the effects of age and gender. The odds of males being able to sit, stand or walk were less than for females but this effect reduced when taking into account the effect of mutation group. However, males had $75 \%$ less odds (OR $0.25,95 \% \mathrm{CI} 0.07,0.96)$ of being able to sit independently compared with females irrespective of age and mutation group (Tables $3 \& 4$ ).

Univariate and multivariate analyses for hand function skills are shown in Table 5. There were no apparent relationships between age group and the ability to grasp large or small objects. In the univariate analysis, those with a truncation between aa172 and aa781 had increased odds of being able to hold a large object compared with those with no functional protein. Taking into account the effects of age and gender, significantly increased odds of being able to grasp a large object persisted for those with a truncation between aa172 and aa781 (OR 4.58, 95\% CI 1.12, 18.75). Males were less likely to be able to grasp a small or a large object in the univariate analyses. Taking into account the effects of age and mutation group, males were more than $80 \%$ less likely to be able to grasp a small object (OR 0.19, 95\% 0.36, 1.00) compared with females (Table 5). 
Univariate and multivariate analyses for communication skills are shown in Table 4. Again there were no relationships between age group and method of communication in the univariate or multivariate analyses in those older than two years. Taking into account the effects of age group and gender and compared to individuals with no functional protein, those with a truncation after aa781 had 6.06 times (95\% CI 1.52-24.18) the odds of using a more advanced form of communication such as use of words. Males were more than $80 \%$ less likely than females to be able to use advanced communication methods in the univariate analysis, and this strong effect persisted after taking into account the effects of age and mutation group (OR $0.17,95 \% \mathrm{CI} 0.04,0.71)$ (Table 4).

\section{DISCUSSION}

For most individuals with the CDKL5 disorder, functional abilities were severely impaired, although there was variability. Most of the youngest children in our study had difficulty with early mobility skills such as rolling, crawling and standing. For those who were older than 18 months, age had little effect on functional abilities, but gross motor and communication skills were more severely affected in males. Independent standing and walking as well as more advanced communication skills were more likely in those with a truncation after aa781 in comparison to those with no functional protein in the gene. This is the first paper to identify this pattern for relationships between genotype and phenotype in the CDKL5 disorder.

Our database has already provided information on the acquisition of developmental milestones where we found that two thirds of females learnt to sit and 
$29 \%$ learnt to walk.[Fehr et al., 2015] We now report functional abilities current at the time of ascertainment to the database where $23 \%$ were walking independently, $8 \%$ used single words and $7 \%$ used sentences. In a previous small French case series $(n=20)$,[Bahi-Buisson et al., 2008] one female (5\%) was able to walk independently, five $(25 \%)$ were able to transfer an object from one hand to the other, five could use babble or single words (25\%) and one girl could speak in sentences (5\%).[Bahi-Buisson et al., 2008] In terms of a milder phenotype Archer and colleagues described a young woman who could walk and swim independently, feed herself using cutlery and speak in phrases.[Archer et al., 2006] More recently, a Spanish study reported on eight females of whom three learned to walk, four had some hand use and two could speak using phrases,[Martínez et al., 2012] but the pathogenicity of variants affecting two of these cases has not been confirmed.[Diebold et al., 2014; Ho et al., 2012] Reports of males with the CDKL5 disorder are rare, but in the largest previous study ( $\mathrm{n}=8)$ all boys had markedly impaired gross motor and communication skills.[Mirzaa et al., 2013] We also found that males were generally more severely affected than females although one male was able to run. Our findings support the thesis that a greater spectrum of functional abilities exists in the CDKL5 disorder than previously described and that males are usually more severely affected than females.

Investigating genotype-phenotype relationship in the CDKL5 disorder is challenging because of the abundance of unique variants [Bahi-Buisson et al., 2012] evident even in the current study with data on 124 confirmed cases included in the analyses.[Fehr et al., 2015] By grouping the variants, we found that those with a truncation after aa781 were more likely to be able to stand or walk independently and 
had better expressive communication abilities than those with no functional protein. Only one other study has specifically examined genotype-phenotype relationships ( $n=26$, range per variant 1-5).[Bahi-Buisson et al., 2012] In this study, the missense variant p.Ala40Val $(n=5)$ and the $C$-terminal nonsense variant $\mathrm{p}$. $\operatorname{Arg} 550 *(n=3)$ were associated with a milder phenotype, whereas the C-terminal frameshift variant c.2635_2636delCT $(n=3)$ was associated with a more severe phenotype. Our current study included two individuals with this latter variant of whom one could walk independently and the other could not. For our analyses, these individuals were grouped with others who also had a mutation in the C-terminal region (the truncation after aa781 group), resulting in a much larger sample and greater potential to reduce sampling error. This mutation group was associated with better functional abilities across the gross motor and communication domains. Otherwise, we found that those with a truncation between aa172 and aa781 rather than those with a truncation after aa781 were more likely to be able to pick up large object than those with no functional protein, although this apparent protective effect did not extend to more advanced hand function skills. Clearly, the impacts that different variants have on protein function and phenotype needs to be further investigated with even larger studies. However, we are the first to have described the findings that together suggest that those with a truncation after aa781 are more mildly affected.

Severe developmental delay is a cardinal feature of the CDKL5 disorder [Fehr et al., 2013] and the gross motor impacts of the CDKL5 disorder would generally be considered more severe than for other disorders such as Rett syndrome. In a sample of 293 individuals with Rett syndrome, more than $90 \%$ learnt to sit and nearly half (46\%) 
learnt to walk during early childhood.[Fehr et al., 2011] Gross motor skills in 99 females with Rett syndrome were then observed using video taken at a median age of 14 years one month [Downs et al., 2008] Compared with Rett syndrome, fewer females with the CDKL5 disorder were able to sit on the floor (67\% vs $76 \%$ ), stand for 20 seconds (25\% vs $30 \%)$ and walk 10 steps forward with no assistance (23\% vs $43 \%)$. During early childhood, the likelihood of acquiring the ability to sit or walk was much higher for females with Rett syndrome than for females with the CDKL5 disorder. However, we have demonstrated that the ability to sit on the floor declined in $21 \%$ of 70 individuals over a 3 to 4 year period,[Foley et al., 2011] and using longitudinal data on 363 individuals followed for up to 20 years, a proportion experienced deterioration in walking from independent or assisted walking to being unable to walk $(\mathrm{n}=55$, 15\%).[Downs et al., in press] Sitting and walking skills can decline over time with any neurodevelopmental disability due to factors such as epilepsy, the development of deformity and general deconditioning, and the median age of the Rett syndrome cohort was older than for females with the CDKL5 disorder (median age five years) in the current study. We acknowledge that we did not see a relationship between gross motor skills and age but further follow up of individuals with the CDKL5 disorder would be important to understand the trajectories of gross motor skills.

In contrast to gross motor skills, hand grasping appeared stronger in the CDKL5 disorder, with a higher proportion of females able to grasp objects (83\%) compared to those with Rett syndrome (70\%, $\mathrm{n}=144$, median age 14 years 10 months).[Downs et al., 2010] Loss of hand skills during a period of regression typically occurs in Rett syndrome $(80 \%)^{3}$ and is a component of the diagnostic criteria.[Neul et al., 2010] 
Regression is less common in the CDKL5 disorder [Fehr et al., 2013] and could explain the better level of hand grasping skill. We previously found that the majority of those with the CDKL5 disorder did not meet the diagnostic criteria for Rett syndrome.[Fehr et al., 2013] Our current findings provide additional detail as to the differences in functional abilities between the two conditions.

It has been suggested that $C D K L 5$ variants cause early-onset infantile epileptic encephalopathy,[Liang et al., 2011; Melani et al., 2011] implying that the epileptic activity contributes to the severe cognitive and behavioural impairment, 'above and beyond that expected from the underlying pathology alone'.[Berg et al., 2010] The developmental processes occurring at the time are thought to influence the impacts of seizures,[Nardou et al., 2013] with early-onset frequent seizures having the greatest impact on cognition.[Vasconcellos et al., 2001] Spontaneous seizures were not present in the first CDKL5 disorder mouse model, however autistic-like behaviours and motor impairments were.[Wang et al., 2012] Therefore these features may be a result of the underlying genetic abnormality rather than the seizures. It would be of interest to further investigate the factors associated with the severity of the functional phenotype and whether they relate to early seizure activity.

Our study included the largest number of individuals with the CDKL5 disorder reported to date, providing a better opportunity to capture the spectrum of clinical presentations. Only a small proportion of individuals in the current study experienced regression of hand and/or communication skills, a mandatory criterion for atypical Rett syndrome including the early seizure variant. We confirm that the CDKL5 disorder is 
an independent clinical entity.[Fehr et al., 2013] The International CDKL5 Disorder Database, used in this study, is the only global data collection developed specifically to collect comprehensive information on this disorder. Most previous studies have reported findings in the context of the CDKL5 disorder being part of the Rett syndrome spectrum, and mainly comprised individual case studies. Even our earlier study [Fehr et al., 2013] was primarily developed to collect information on Rett syndrome.[Fyfe et al., 2003] Therefore we acknowledge that some of the measures we used in the current study were originally designed for Rett syndrome, but they are generally applicable to individuals with severe functional impairments allowing comparison across conditions. Our questionnaire was grounded in the expressed views of our consumer reference group who argued that detailed description of motor skills was critical to understanding their child's condition. We acknowledge that our grouping of individual mutations may not be optimal and that future criteria for grouping may become evident with time. As the first comprehensive description of functional abilities, our study is based on parentreport data, with its use supported by previous findings that parent report of functional abilities is likely to be accurate.[Bodnarchuk and Eaton 2004; Harvey et al., 2010] We coded data into broader categories which would be relatively crude but would have more validity. Therefore we believe that we have captured some of the true variability present in the CDKL5 disorder. Planned future video data collection will assist in confirming our findings and where possible collection of clinical data. It is also likely that we may have an over-representation of families from higher socio-economic backgrounds because of the requirement for genetic testing to confirm the diagnosis. Although our study is the largest to date, the genetic heterogeneity still limits the power 
to identify genotype-phenotype relationships and therefore even greater numbers are needed.

In summary, we have provided information on functional abilities in the largest sample of individuals with the CDKL5 disorder to date. In doing so, we have confirmed that males are more severely impaired than females and found that there is little variation in skills with age. Our findings also highlight the variability within this disorder and particularly that milder developmental impairments may be associated with later truncations in the $C D K L 5$ gene. More research with regard to the effects of genotype and epilepsy are needed.

\section{List of abbreviations}

CDKL5 cyclin-dependent kinase-like 5

aa amino acid

OR odds ratio

\section{ACKNOWLEDGEMENTS}

The authors would like to acknowledge the families and caregivers who have participated in the International CDKL5 Disorder Database by completing questionnaires on their child. The authors would also like to thank the International Foundation for CDKL5 Research for their ongoing support and assistance and Dr Alison Anderson for her assistance in establishing and designing the database infrastructure. SF received an Australian Postgraduate Award, University of Western Australia Safety-Net Top-Up Scholarship, the Stan and Jean Perron Top-Up Scholarship 
and the Stan and Jean Perron Award for Excellence. Data collection was also supported by an NHMRC Program Grant \#572742 (Dr Jenny Downs) and NHMRC Senior Research Fellowship \#572568 (Dr Helen Leonard). Dr Ho was supported by an International Rett Syndrome Foundation database support grant. The authors declare no conflict of interest.

References

Archer HL, Evans J, Edwards S, Colley J, Newbury-Ecob R, O'Callaghan F, Huyton M, O'Regan M, Tolmie J, Sampson J, Clarke A, Osborne J. 2006. CDKL5 mutations cause infantile spasms, early onset seizures, and severe mental retardation in female patients. J Med Genet 43(9):729-734.

Artuso R, Mencarelli MA, Polli R, Sartori S, Ariani F, Pollazzon M, Marozza A, Cilio MR, Specchio N, Vigevano F, Vecchi M, Boniver C, Dalla Bernardina B, Parmeggiani A, Buoni S, Hayek G, Mari F, Renieri A, Murgia A. 2010. Earlyonset seizure variant of Rett syndrome: Definition of the clinical diagnostic criteria. Brain Dev 32(1):17-24.

Bahi-Buisson N, Nectoux J, Rosas-Vargas H, Milh M, Boddaert N, Girard B, Cances C, Ville D, Afenjar A, Rio M, Héron D, N'guyen Morel MA, Arzimanoglou A, Philippe C, Jonveaux P, Chelly J, Bienvenu T. 2008. Key clinical features to identify girls with CDKL5 mutations. Brain 131(Pt 10):2647-2661.

Bahi-Buisson N, Villeneuve N, Caietta E, Jacquette A, Maurey H, Matthijs G, Van Esch H, Delahaye A, Moncla A, Milh M, Zufferey F, Diebold B, Bienvenu T. 2012. Recurrent mutations in the CDKL5 gene: Genotype-phenotype relationships. Am J Med Genet A 158A(7):1612-1619. 
Bartnik M, Derwinska K, Gos M, Obersztyn E, Kolodziejska K, Erez A, SzpechtPotocka A, Fang P, Terczynska I, Mierzewska H, Lohr N, Bellus G, Reimschisel T, Bocian E, Mazurczak T, Cheung S, Stankiewicz P. 2011. Early-onset seizures due to mosaic exonic deletions of CDKL5 in a male and two females. Genet Med 13(5):447-452.

Berg AT, Berkovic SF, Brodie MJ, Buchhalter J, Cross JH, Van Emde Boas W, Engel J, French J, Glauser TA, Mathern GW. 2010. Revised terminology and concepts for organization of seizures and epilepsies: report of the ILAE Commission on Classification and Terminology, 2005-2009. Epilepsia 51(4):676-685.

Bertani I, Rusconi L, Bolognese F, Forlani G, Conca B, De Monte L, Badaracco G, Landsberger N, Kilstrup-Nielsen C. 2006. Functional consequences of mutations in CDKL5, an X-linked gene involved in infantile spasms and mental retardation. J Biol Chem 281(42):32048-32056.

Bodnarchuk JL, Eaton WO. 2004. Can parent reports be trusted?: Validity of daily checklists of gross motor milestone attainment. J Appl Dev Psychol 25(4):481490.

Diebold B, Delépine C, Gataullina S, Delahaye A, Nectoux J, Bienvenu T. 2014. Mutations in the C-terminus of CDKL5: proceed with caution. Eur J Hum Genet 22(2):270-272.

Downs J, Bebbington A, Jacoby P, Williams AM, Ghosh S, Kaufmann WE, Leonard H. 2010. Level of purposeful hand function as a marker of clinical severity in Rett syndrome. Dev Med Child Neurol 52(9):817-823. 
Downs J, Torode I, Wong K, Ellaway C, Elliott EJ, Christodoulou J, Jacoby P, Thomson MR, Izatt MT, Askin GN, McPhee BI, Bridge C, Cundy P, Leonard H. in press. The natural history of scoliosis in females with Rett syndrome. Spine.

Downs JA, Bebbington A, Jacoby P, Msali M, McLlroy O, Fyfe S, Bahi-Buisson N, Kaufmann WE, Leonard H. 2008. Gross motor profile in Rett syndrome as determined by video analysis. Neuropediatrics 39(4):205-210.

Evans JC, Archer HL, Colley JP, Ravn K, Nielsen JB, Kerr A, Williams E, Christodoulou J, Gecz J, Jardine PE, Wright MJ, Pilz DT, Lazarou L, Cooper DN, Sampson JR, Butler R, Whatley SD, Clarke AJ. 2005. Early onset seizures and Rett-like features associated with mutations in CDKL5. Eur J Hum Genet 13(10):1113-1120.

Fehr S, Bebbington A, Ellaway C, Rowe P, Leonard H, Downs J. 2011. Altered attainment of developmental milestones influences the age of diagnosis of rett syndrome. J Child Neurol 26(8):980-987.

Fehr S, Leonard H, Ho G, Williams S, de Klerk N, Forbes D, Christodoulou J, Downs J. 2015. There is variability in the attainment of developmental milestones in the CDKL5 disorder. J Neurodev Disord 7(1):2.

Fehr S, Wilson M, Downs J, Williams S, Murgia A, Sartori S, Vecchi M, Ho G, Polli R, Psoni S, Bao X, de Klerk N, Leonard H, Christodoulou J. 2013. The CDKL5 disorder is an independent clinical entity associated with early-onset encephalopathy. Eur J Hum Genet 21(3):266-273.

Foley KR, Downs J, Bebbington A, Jacoby P, Girdler S, Kaufmann WE, Leonard H. 2011. Change in gross motor abilities of girls and women with rett syndrome over a 3- to 4-year period. J Child Neurol 26(10):1237-1245. 
Fyfe S, Cream A, de Klerk N, Christodoulou J, Leonard H. 2003. InterRett and RettBASE: International Rett Syndrome Association databases for Rett syndrome. J Child Neurol 18:709-713.

Hagebeuk EE, Van Den Bossche RA, DE Weerd AW. 2013. Respiratory and sleep disorders in female children with atypical Rett syndrome caused by mutations in the CDKL5 gene. Dev Med Child Neurol 55(5):480-484.

Harvey A, Baker R, Morris ME, Hough J, Hughes M, Graham HK. 2010. Does parent report measure performance? A study of the construct validity of the Functional Mobility Scale. Dev Med Child Neurol 52(2):181-185.

Ho G, Gold W, Williamson SL, Christodoulou J. 2012. Pathogenicity of C-terminal mutations in CDKL5. J Pediatr Epilep 1(3):185-186.

Jähn J, Caliebe A, von Spiczak S, Boor R, Stefanova I, Stephani U, Helbig I, Muhle H. 2013. CDKL5 Mutations as a Cause of Severe Epilepsy in Infancy: Clinical and Electroencephalographic Long-term Course in 4 Patients. J Child Neurol 28(7):937-941

Kalscheuer VM, Tao J, Donnelly A, Hollway G, Schwinger E, Kubart S, Menzel C, Hoeltzenbein M, Tommerup N, Eyre H, Harbord M, Haan E, Sutherland GR, Ropers HH, Gecz J. 2003. Disruption of the serine/threonine kinase 9 gene causes severe X-linked infantile spasms and mental retardation. Am J Hum Genet 72(6):1401-1411.

Liang JS, Shimojima K, Takayama R, Natsume J, Shichiji M, Hirasawa K, Imai K, Okanishi T, Mizuno S, Okumura A, Sugawara M, Ito T, Ikeda H, Takahashi Y, Oguni H, Osawa M, Yamamoto T. 2011. CDKL5 alterations lead to early epileptic encephalopathy in both genders. Epilepsia 52(10):1835-1842. 
Martínez AR, Armstrong J, Gerotina E, Fons C, Campistol J, Pineda M. 2012. CDKL5 in different atypical Rett syndrome variants: Description of the first eight patients from Spain. J Pediatr Epilep 1(1):27-35.

Melani F, Mei D, Pisano T, Savasta S, Franzoni E, Ferrari A, Marini C, Guerrini R. 2011. CDKL5 gene-related epileptic encephalopathy: electroclinical findings in the first year of life. Dev Med Child Neurol:354-360.

Mirzaa GM, Paciorkowski AR, Marsh ED, Berry-Kravis EM, Medne L, Alkhateeb A, Grix A, Wirrell EC, Powell BR, Nickels KC, Burton B, Paras A, Kim K, Chung W, Dobyns WB, Das S. 2013. CDKL5 and ARX mutations in males with earlyonset epilepsy. Pediatr Neurol 48(5):367-377.

Nardou R, Ferrari DC, Ben-Ari Y. 2013. Mechanisms and effects of seizures in the immature brain. Semin Fetal Neonatal Med 18(4):175-184.

Nemos C, Lambert L, Giuliano F, Doray B, Roubertie A, Goldenberg A, Delobel B, Layet V, N'Guyen M A, Saunier A, Verneau F, Jonveaux P, Philippe C, N'Guyen MA. 2009. Mutational spectrum of CDKL5 in early-onset encephalopathies: a study of a large collection of French patients and review of the literature. Clin Genet 76(4):357-371.

Neul J, Kaufmann W, Glaze D, Christodoulou J, Clarke A, Bahi-Buisson N, Leonard H, Bailey M, Schanen N, Zappella M, Renieri A, Huppke P, Percy A, Consortium R. 2010. Rett Syndrome: Revised Diagnostic Criteria and Nomenclature. Ann Neurol 68(6):944-950.

Olson HE, Poduri A. 2012. CDKL5 mutations in early onset epilepsy: Case report and review of the literature. J Pediatr Epilep 1(3):151-159. 
Pini G, Bigoni S, Engerström IW, Calabrese O, Felloni B, Scusa MF, Di Marco P, Borelli P, Bonuccelli U, Julu PO, Nielsen JB, Morin B, Hansen S, Gobbi G, Visconti P, Pintaudi M, Edvige V, Romanelli A, Bianchi F, Casarano M, Battini R, Cioni G, Ariani F, Renieri A, Benincasa A, Delamont RS, Zappella M, group E. 2013. Variant of Rett Syndrome and CDKL5 Gene: Clinical and Autonomic Description of 10 Cases. Neuropediatrics 44(4):237-238.

Pountney TE, Cheek L, Green E, Mulcahy C, Nelham R. 1999. Content and Criterion Validation of the Chailey Levels of Ability. Physiotherapy 85(8):410-416.

Rowland C, Fried-Oken M. 2010. Communication matrix: A clinical and research assessment tool targeting children with severe communication disorders. J Pediatr Rehabil Med 3(4):319-329.

Tao J, Van Esch H, Hagedorn-Greiwe M, Hoffmann K, Moser B, Raynaud M, Sperner J, Fryns J, Schwinger E, Gecz J, Ropers H, Kalscheuer V. 2004. Mutations in the X-linked cyclin-dependent kinase-like 5 (CDKL5/STK9) gene are associated with severe neurodevelopmental retardation. Am J Hum Genet 75(6):1149-1154.

Vasconcellos E, Wyllie E, Sullivan S, Stanford L, Bulacio J, Kotagal P, Bingaman W. 2001. Mental Retardation in Pediatric Candidates for Epilepsy Surgery: The Role of Early Seizure Onset. Epilepsia 42(2):268-274.

Wang IT, Allen M, Goffin D, Zhu X, Fairless AH, Brodkin ES, Siegel SJ, Marsh ED, Blendy JA, Zhou Z. 2012. Loss of CDKL5 disrupts kinome profile and eventrelated potentials leading to autistic-like phenotypes in mice. Proc Natl Acad Sci U S A 109(52):21516-21521.

Weaving LS, Christodoulou J, Williamson SL, Friend KL, McKenzie OL, Archer H, Evans J, Clarke A, Pelka GJ, Tam PP, Watson C, Lahooti H, Ellaway CJ, 
Bennetts B, Leonard H, Gécz J. 2004a. Mutations of CDKL5 cause a severe neurodevelopmental disorder with infantile spasms and mental retardation. Am J Hum Genet 75(6):1079-1093.

Weaving LS, Christodoulou J, Williamson SL, Friend KL, McKenzie OL, Archer HL, Evans J, Clarke AJ, Pelka GJ, Tam PP, Watson C, Lahooti H, Ellaway CJ, Bennetts B, Leonard H, Gecz J. 2004b. Mutations of CDKL5 cause a severe neurodevelopmental disorder with infantile spasms and mental retardation. Am J Hum Genet 75(6):1079-1093.

White R, Ho G, Schmidt S, Scheffer IE, Fischer A, Yendle SC, Bienvenu T, Nectoux J, Ellaway CJ, Darmanian A, Tong X, Cloosterman D, Bennetts B, Kalra V, Fullston T, Gecz J, Cox TC, Christodoulou J. 2010. Cyclin-dependent kinaselike 5 (CDKL5) mutation screening in Rett syndrome and related disorders. Twin Res Hum Genet 13(2):168-178.

HIDDEN TEXT FOUND PLEASE VERIFY IT FROM INPUT DOC FILE THEN DELETE IT IF NOT REQUIRE::::::********************** </errorimage>

Table 1. Level of assistance needed to undertake gross motor tasks for females and males 
Females (n, \%)

\begin{tabular}{|c|c|c|c|c|c|c|}
\hline \multicolumn{2}{|c|}{ Gross motor task } & \multirow{2}{*}{$\begin{array}{c}\text { No } \\
\text { assistance } \\
65(67)\end{array}$} & \multirow{2}{*}{$\begin{array}{c}\text { With } \\
\text { assistance }\end{array}$} & \multirow{2}{*}{$\begin{array}{c}\text { Maximal } \\
\text { assistance/ } \\
\text { unable }\end{array}$} & \multirow{2}{*}{$\begin{array}{c}\begin{array}{c}\text { Total } \\
\text { number }\end{array} \\
97\end{array}$} & \multirow{2}{*}{$\begin{array}{r}\begin{array}{c}\text { No } \\
\text { assistan }\end{array} \\
4(27\end{array}$} \\
\hline \multirow{3}{*}{ Sitting $^{\mathrm{a}}$} & on the floor for 10 seconds & & & & & \\
\hline & on a chair for 10 seconds & $51(54)$ & $18(19.0)$ & $26(27)$ & 95 & $2(13$ \\
\hline & on a stool for 10 seconds & $30(31)$ & $30(31)$ & $37(38)$ & 97 & $1(7)$ \\
\hline \multirow{3}{*}{ Standing $^{\mathrm{a}}$} & 3 seconds & $29(30)$ & $27(28)$ & $41(42)$ & 97 & $1(7)$ \\
\hline & 10 seconds & $24(25)$ & $25(26)$ & $48(50)$ & 97 & $1(7)$ \\
\hline & 20 seconds & $24(25)$ & $22(23)$ & $51(53)$ & 97 & $1(7)$ \\
\hline \multirow[t]{2}{*}{ Transition $^{\mathrm{a}}$} & from sitting to standing & $20(21)$ & $21(22)$ & $56(58)$ & 97 & $1(7)$ \\
\hline & 10 steps forward & $22(23)$ & $14(14)$ & $61(63)$ & 97 & $1(7)$ \\
\hline \multirow{4}{*}{ Walking $^{\mathrm{a}}$} & $\begin{array}{l}\text { side-steps (to step around } \\
\text { furniture) }\end{array}$ & $21(22)$ & $14(14)$ & $62(64)$ & 97 & $1(7)$ \\
\hline & able to turn 180 degrees & $20(21)$ & $9(9)$ & $68(70)$ & 97 & $1(7)$ \\
\hline & up or down a slope & $10(10)$ & $20(21)$ & $67(69)$ & 97 & $1(7)$ \\
\hline & stepping over an obstacle & $15(16)$ & $14(14)$ & $68(70)$ & 97 & $1(7)$ \\
\hline \multirow{3}{*}{$\begin{array}{l}\text { Complex } \\
\text { transition } \\
\text { and } \\
\text { running }\end{array}$} & from the floor to standing & $19(23)$ & $17(20)$ & $48(57)$ & 84 & $1(8)$ \\
\hline & $\begin{array}{l}\text { bending to touch floor and } \\
\text { returning to standing }\end{array}$ & $17(20)$ & $6(7)$ & $61(73)$ & 84 & $1(8)$ \\
\hline & running & $11(13)$ & $4(5)$ & $69(82)$ & 84 & $1(8)$ \\
\hline
\end{tabular}

${ }^{a}$ General gross motor tasks for individuals aged $\geq 1.5$ years (females $n=97$, males $n=15$ ).

${ }^{\mathrm{b}}$ Complex gross motor tasks for individuals $\geq 3$ years (females $n=84$, males $n=12$ ).

Table 2 The distribution of grasping skills and methods of expressive communication methods for females by age group and males

Females

$\begin{array}{ccccc} & \leq 1.5 \text { years } & 1.5 \text { to } 7 \text { years } & 7 \text { to } 13 \text { years } & 13 \text { years and } \\ \text { Grasping task } & (\mathrm{n}=11) & (\mathrm{n}=48) & (\mathrm{n}=30) & \begin{array}{c}\text { over } \\ (\mathrm{n}=14)\end{array}\end{array}$

No ability to grasp or needs help to grasp a large object

5

$(14.3 \%)$

Can grasp, pick up, and hold at least 1 type of large object ${ }^{\mathrm{a}}$

$\begin{array}{ccc}4 & 16 & 6 \\ (36 \%) & (33 \%) & (20 \%)\end{array}$

5

(14.3\%)

$(25.7 \%)$

1

$(7 \%)$ 
Able to grasp a small ${ }^{\mathrm{b}}$ and a large object

Communication method

No or simple communication

Complex gestures, concrete symbols and vocalisations

Spoken language, signs and abstract symbol
2

$(4.9 \%)$

$\leq 1.5$ years

$(\mathrm{n}=11)$

7

$(64 \%)$

3

$(27 \%)$

1

$(9 \%)$
16

$(39.0 \%)$

1.5 - 7 years

$(\mathrm{n}=49)$

16

$(33 \%)$

18

$(37 \%)$

15

$(30 \%)$
15

$(36.6 \%)$

8

(19.5\%)

$\geq 13$ years

$(\mathrm{n}=15)$

6

(40\%)

(26\%)

15

(49\%)

5

(33\%)

8

(26\%)
4 (27\%)

A large object could be a cup, eating utensil, small toy or a small ball.

${ }^{\mathrm{b}}$ A small object could be a small piece of food such as a sultana or piece of apricot.

Table 3: Univariate and multivariate relationships between genotype, age, gender and the gross motor skills of sitting on the floor and standing.

\begin{tabular}{|c|c|c|c|c|}
\hline Sitting on floor 10 seconds ${ }^{a}$ & $\mathrm{~N}(\%)$ & OR $(95 \% \mathrm{CI})$ & $\mathrm{P}$ & OR $(95 \% \mathrm{CI})$ \\
\hline No functional protein & $35(34.6)$ & \multicolumn{2}{|l|}{ Baseline } & Baseline $^{\mathrm{b}}$ \\
\hline Missense/in-frame variant within catalytic region & $30(29.7)$ & $1.50(0.54,4.13)$ & 0.432 & $1.45(0.51,4.08)$ \\
\hline Truncation after aa 172 and before aa 781 & $23(22.8)$ & $0.98(0.34,2.82)$ & 0.963 & $0.94(0.32,2.80)$ \\
\hline Truncation after aa 781 & $13(12.9)$ & $4.12(0.79,21.45)$ & 0.092 & $4.04(0.77,21.15)$ \\
\hline 1.5 to 7 years & $51(50.5)$ & \multicolumn{2}{|l|}{ Baseline } & Baseline $^{\mathrm{b}}$ \\
\hline 7 to 13 years & $33(32.7)$ & $1.08(0.46,2.56)$ & 0.859 & $0.97(0.38,2.48)$ \\
\hline 13 years and over & $17(16.8)$ & $0.76(0.26,2.23)$ & 0.622 & $0.83(0.26,2.68)$ \\
\hline Female & $89(88.1)$ & \multicolumn{2}{|l|}{ Baseline } & - \\
\hline Male & $12(11.9)$ & $0.18(0.05,0.61)$ & 0.006 & - \\
\hline \multicolumn{5}{|l|}{ Stand 20 seconds ${ }^{a}$} \\
\hline No functional protein & $35(34.6)$ & \multicolumn{2}{|l|}{ Baseline } & Baseline $^{b}$ \\
\hline Missense/in-frame variant within catalytic region & $30(29.7)$ & $1.93(0.49,7.65)$ & 0.345 & $1.98(0.49,8.05)$ \\
\hline Truncation after aa 172 and before aa 781 & $23(22.8)$ & $2.74(0.68,11.05)$ & 0.158 & $2.62(0.63,10.92)$ \\
\hline Truncation after aa 781 & $13(12.9$ & $6.64(1.47,30.00)$ & 0.014 & $6.51(1.42,29.82)$ \\
\hline 1.5 to 7 years & $51(50.5)$ & \multicolumn{2}{|l|}{ Baseline } & Baseline $^{\mathrm{b}}$ \\
\hline 7 to 13 years & $33(32.7)$ & $1.88(0.72,4.94)$ & 0.200 & $1.47(0.50,4.32)$ \\
\hline 13 years and over & $17(16.8)$ & $0.85(0.21,3.47)$ & 0.826 & $1.07(0.23,4.85)$ \\
\hline Female & $89(88.1)$ & \multicolumn{2}{|l|}{ Baseline } & - \\
\hline Male & $12(11.9)$ & $0.22(0.03,1.74)$ & 0.150 & - \\
\hline
\end{tabular}


restricted to individuals 18 months or older, $\mathrm{n}=101$; ${ }^{\mathrm{b}}$ adjusted for age or mutation group; ${ }^{\mathrm{c}}$ adjusted for age group, mutation group and gender

Table 4: Univariate and multivariate relationships between genotype, age, gender and the gross motor skill of walking and communication method.

\begin{tabular}{|c|c|c|c|c|c|c|}
\hline & \multicolumn{3}{|c|}{ Univariate models } & \multicolumn{3}{|c|}{ Multivariate models } \\
\hline$e^{e p s}{ }^{a}$ & $\mathrm{~N}(\%)$ & OR $(95 \% \mathrm{CI})$ & $\mathrm{P}$ & OR $(95 \% \mathrm{CI})$ & $\mathrm{P}$ & OR $(95 \% \mathrm{CI})$ \\
\hline al protein & $35(34.6)$ & \multicolumn{2}{|l|}{ Baseline } & \multicolumn{2}{|l|}{ Baseline $^{c}$} & Baseline \\
\hline a-frame variant within catalytic region & $30(29.7)$ & $1.94(0.49,7.65)$ & 0.345 & $1.96(0.48,7.97)$ & 0.348 & $1.89(0.46,7.80)$ \\
\hline after aa 172 and before aa 781 & $23(22.8)$ & $2.15(0.51,9.06)$ & 0.296 & $2.16(0.50,9.36)$ & 0.305 & $1.95(0.44,8.66)$ \\
\hline after aa 781 & $13(12.9)$ & $4.84(1.05,22.31)$ & 0.043 & $4.85(1.04,22.63)$ & 0.045 & $4.28(0.89,20.50$ \\
\hline ars & $51(50.5)$ & \multicolumn{2}{|l|}{ Baseline } & \multicolumn{2}{|l|}{ Baseline $^{\mathrm{c}}$} & Baseline \\
\hline rs & $33(32.7)$ & $1.42(0.52,3.87)$ & 0.488 & $1.06(0.35,3.25)$ & 0.917 & $1.10(0.36,3.41)$ \\
\hline d over & $17(16.8)$ & $0.85(0.21,3.47)$ & 0.826 & $1.05(0.24,4.72)$ & 0.945 & $1.06(0.24,4.80)$ \\
\hline & $89(88.1)$ & \multicolumn{2}{|l|}{ Baseline } & \multicolumn{2}{|l|}{-} & Baseline \\
\hline & $12(11.9)$ & $0.24(0.03,1.96)$ & 0.184 & - & - & $0.45(0.05,3.95)$ \\
\hline \multicolumn{7}{|l|}{ cation $^{b}$} \\
\hline hal protein & $31(33.7)$ & \multicolumn{2}{|l|}{ Baseline } & \multicolumn{2}{|l|}{ Baseline $^{c}$} & Baseline \\
\hline -frame variant within catalytic region & $27(29.4)$ & $1.41(0.53,3.76)$ & 0.448 & $1.41(0.52,3.86)$ & 0.497 & $1.20(0.42,3.39)$ \\
\hline after aa 172 and before aa 781 & $22(23.9)$ & $1.26(0.44,3.57)$ & 0.768 & $1.26(0.43,3.64)$ & 0.675 & $0.8(0.29,2.70)$ \\
\hline after aa 781 & $12(13.0)$ & $8.69(2.30,32.90)$ & 0.002 & $8.68(2.26,33.38)$ & 0.002 & $6.06(1.52,24.18)$ \\
\hline $\operatorname{ars}$ & $43(46.7)$ & Baseline & & \multicolumn{2}{|l|}{ Baseline $^{\mathrm{c}}$} & Baseline \\
\hline rs & $33(35.9)$ & $1.04(0.48,2.29)$ & 0.912 & $\begin{array}{c}1.04 \\
(0.44,2.46)\end{array}$ & 0.928 & $\begin{array}{c}1.08 \\
(0.44,2.60)\end{array}$ \\
\hline \multirow[t]{3}{*}{ d over } & $\begin{array}{c}16 \\
(17.4)\end{array}$ & $0.75(0.26,2.13)$ & 0.591 & $\begin{array}{c}1.00 \\
(0.32,3.17)\end{array}$ & 0.997 & $\begin{array}{c}0.91 \\
(0.28,2.93)\end{array}$ \\
\hline & $\begin{array}{c}80 \\
(87.0)\end{array}$ & Baseli & & \multicolumn{2}{|l|}{ Baseline } & Baseline \\
\hline & $\begin{array}{c}12 \\
(13.0)\end{array}$ & $.16(0.05,0.53)$ & 0.003 & - & - & $0.17(0.04,0.71)$ \\
\hline
\end{tabular}

restricted to individuals 18 months or older, $\mathrm{n}=101$; ${ }^{\mathrm{b}}$ restricted to individuals 2 years and older, $n=92 ;{ }^{c}$ adjusted for age or mutation group; ${ }^{\mathrm{d}}$ adjusted for age group, mutation group and gender

Table 5. Univariate and multivariate relationships between genotype, age, gender and hand function $(\mathrm{n}=109)$

\begin{tabular}{|c|c|c|c|c|c|c|c|c|}
\hline & \multirow{2}{*}{$\begin{array}{c}\text { No } \\
\text { independent } \\
\text { grasp }\end{array}$} & \multicolumn{6}{|c|}{ Able to grasp, pick up, and hold a large object } & \multirow{2}{*}{$\begin{array}{c}\text { Able to gras } \\
\text { Univa }\end{array}$} \\
\hline & & & \multicolumn{2}{|c|}{ Univariate } & \multicolumn{2}{|c|}{ Multivariate $^{\mathrm{a}}$} & \multirow[b]{2}{*}{$\begin{array}{c}\mathrm{n} \\
(\%)\end{array}$} & \\
\hline & $\begin{array}{c}\mathrm{n} \\
(\%)\end{array}$ & $\begin{array}{c}\mathrm{n} \\
(\%)\end{array}$ & $\begin{array}{c}\text { OR } \\
(95 \% \mathrm{CI})\end{array}$ & $\begin{array}{c}\mathrm{P} \\
\text { value }\end{array}$ & OR $(95 \% \mathrm{CI})$ & $\begin{array}{c}\mathrm{P} \\
\text { value }\end{array}$ & & $\begin{array}{c}\text { OR }(95 \% \\
\text { CI })\end{array}$ \\
\hline No functional protein & $20(50)$ & $\begin{array}{c}5 \\
(13)\end{array}$ & & Base & ine & & $\begin{array}{c}15 \\
(37)\end{array}$ & \\
\hline
\end{tabular}




\begin{tabular}{|c|c|c|c|c|c|c|c|c|}
\hline $\begin{array}{l}\text { Missense/in-frame } \\
\text { variant within } \\
\text { catalytic region }\end{array}$ & $10(32)$ & $\begin{array}{c}10 \\
(32)\end{array}$ & $\begin{array}{c}4.00 \\
(1.07,14.89)\end{array}$ & 0.039 & $\begin{array}{c}3.36 \\
(0.85,13.28)\end{array}$ & 0.084 & $\begin{array}{c}11 \\
(36)\end{array}$ & $\begin{array}{c}1.47 \\
(0.49,4.35)\end{array}$ \\
\hline $\begin{array}{l}\text { Truncation after aa } \\
172 \text { and before aa } 781\end{array}$ & $8(32)$ & $\begin{array}{c}11 \\
(44)\end{array}$ & $\begin{array}{c}5.50 \\
(1.44,20.96)\end{array}$ & 0.013 & $\begin{array}{c}4.58 \\
(1.12,18.75)\end{array}$ & 0.034 & $6(24)$ & $\begin{array}{c}1.00 \\
(0.28,3.50)\end{array}$ \\
\hline $\begin{array}{l}\text { Truncation after aa } \\
781\end{array}$ & $3(23)$ & $\begin{array}{c}3 \\
(23)\end{array}$ & $\begin{array}{c}4.00 \\
(0.61,26.12)\end{array}$ & 0.148 & $\begin{array}{c}2.97 \\
(0.43,20.74)\end{array}$ & 0.271 & $7(54)$ & $\begin{array}{c}3.11 \\
(0.69,14.07)\end{array}$ \\
\hline Below 1.5 years & $5(42)$ & $\begin{array}{c}4 \\
(33)\end{array}$ & \multicolumn{4}{|c|}{ Baseline } & $3(25)$ & \\
\hline 1.5 to 7 years & $17(35)$ & $\begin{array}{c}17 \\
(35)\end{array}$ & $\begin{array}{c}1.25 \\
(0.28,5.47)\end{array}$ & 0.767 & $\begin{array}{c}1.06 \\
(0.22,5.21)\end{array}$ & 0.939 & $\begin{array}{c}15 \\
(30)\end{array}$ & $\begin{array}{c}1.47 \\
(0.30,7.22)\end{array}$ \\
\hline 7 to 13 years & $12(37)$ & $\begin{array}{c}7 \\
(22)\end{array}$ & $\begin{array}{c}0.73 \\
(0.14,3.65)\end{array}$ & 0.701 & $\begin{array}{c}0.58 \\
(0.10,3.31)\end{array}$ & 0.543 & $\begin{array}{c}13 \\
(41)\end{array}$ & $\begin{array}{c}1.80 \\
(0.35,9.24)\end{array}$ \\
\hline 13 years and over & $7(44)$ & $1(6)$ & $\begin{array}{c}0.18 \\
(0.02,2.12)\end{array}$ & 0.172 & $\begin{array}{c}0.20 \\
(0.02,2.64)\end{array}$ & 0.225 & $8(50)$ & $\begin{array}{c}1.90 \\
(0.33,11.01)\end{array}$ \\
\hline Female & $32(33)$ & $\begin{array}{l}27 \\
(28)\end{array}$ & Baseline & & & & $\begin{array}{c}37 \\
(39)\end{array}$ & \\
\hline Male & $9(69)$ & $\begin{array}{c}2 \\
(15)\end{array}$ & $\begin{array}{c}0.26 \\
(0.05,1.32)\end{array}$ & 0.106 & $\begin{array}{c}0.41 \\
(0.07,2.30)\end{array}$ & 0.308 & $2(15)$ & $\begin{array}{c}0.19 \\
(0.04,0.96)\end{array}$ \\
\hline
\end{tabular}

Effect of mutation group adjusted for age group and gender, effect of age group adjusted for mutation group and gender, effect of gender adjusted for mutation group and age group.

OR, odds ratio; $\mathrm{CI}$, confidence interval 


\section{University Library}

\section{- M M N E R VA A gateway to Melbourne's research publications}

Minerva Access is the Institutional Repository of The University of Melbourne

Author/s:

Fehr, S;Downs, J;Ho, G;de Klerk, N;Forbes, D;Christodoulou, J;Williams, S;Leonard, H

Title:

Functional Abilities in Children and Adults with the CDKL5 Disorder

Date:

2016-11-01

Citation:

Fehr, S., Downs, J., Ho, G., de Klerk, N., Forbes, D., Christodoulou, J., Williams, S. \& Leonard, H. (2016). Functional Abilities in Children and Adults with the CDKL5 Disorder. AMERICAN JOURNAL OF MEDICAL GENETICS PART A, 170 (11), pp.2860-2869. https:// doi.org/10.1002/ajmg.a.37851.

Persistent Link:

http://hdl.handle.net/11343/291625 